\title{
A Review on Electrospinning Technique and Its Application in the Field Of Nanoencapsulation of Bioactive Compounds
}

\author{
Dhaval Raval and Vimal Ramani*
}

Dairy Microbiology Department, College of Dairy Science And Post Graduate Institute of Dairy Education and Research, Kamdhenu University, Amreli-365601, Gujarat, India

*Corresponding author

\section{A B S T R A C T}

Keywords

Electrospinning,

Electro-

hydrodynamic, Food

coating, Drug

targeting, Nanofiber

Article Info

Accepted:

20 June 2019

Available Online:

10 July 2019
Electrospinning is an electro-hydrodynamic process, when a polymer solution can be spun by the use of high potential electric field to obtain nanofibers. Electrospinning techniques are a gainful and flexible method to apply electrostatic force to form fibers in the 100nm range. Electrospinning instrument have mainly three components in which a supply of high voltage, a spinneret and target collector plate. Electrospun fibers have a lot of structural and functional advantages. So, this technique have so many applications and used in food coating, drug targeting, filters, defensive cloths, etc. This review provides a basic idea about the electrospinning process, principle mechanism, and application in food and other industries.

\section{Introduction}

The multidisciplinary aspects of the rising the field of nanotechnology have given a major development to food researchers for the improvement of novel useful foods and food packaging materials (Sozer and Kokini, 2009).

Electrospinning is an economical and one of a kind technique for creating polymer fibers of $100 \mathrm{~nm}$ diameter range. Electrospun fibers have great potential as vehicles used for drug release, bio-molecular sensors, nanoencapsulation of bioactive molecules and ultra-filtration media (AnuBhushani and Anandharamakrishnan, 2014).
Electrospinning process was licensed by Formhals (1934) for the formation of polymer fibers utilizing electrostatic force. In the electrospinning technique, fibers should be thinner from other methods.

Electrospinning is electro-hydrodynamic processes, where a polymer solution can be spun by the application of high potential electric field to obtain fibers (Wu and Clark, 2008).

Electrospinning instrument have mainly three components which are a spinneret, supply of high voltage, and target collector plate. Two electrodes are used in which one is connected 
to polymer solution niddle and second to the collector. For constant flow, a syringe siphon was utilized (Kessick et al., 2004). Electrospinning process utilizes high voltage $(1-30 \mathrm{Kv})$ which decreases the surface pressure and resulting thin fiber being drawn out.

\section{Principle of electrospinning technique}

Electrostatic force can be utilized in electrospinning to frame a fine fiber from the polymer solution (Frenot and Chronakis, 2003). Electrospinning instrument having the main four components i.e., a spinneret, high voltage supply, and target collector plate in which high voltage supply is used to induce a excess electric charge within the liquid polymer. A fiber strand collects to the grounded collector. The fluid polymer is siphoned from the spinneret at a consistent volume stream utilizing a syringe siphon (Anu et al., 2014).

When the electric field is carried out to a liquid or polymer solution, an electrostatic charge accumulates on the tip of this droplet. This charge produces electrostatic repulsive force along with its work again the surface tension of droplet. Hence, the droplet is deformed and change into the broadly spherical surface to an elongated cone shape is known as taylor cone (Reneker et al., 2000, Yarin et al., 2001).

When the surface strain of liquid droplet conquers a charged polymer jet eject from the capillary spinneret. This jet may take a complex route and it subjected to instabilities induced by electric charges is called whipping instability (Doshi and Reneker, 1995). This whipping instability or twisting movement of the jet getting elongation and quick evaporation of the solvent take place and solid thin fiber is deposited to the collector ( $\mathrm{Yu}$ et al., 2009).
As per Sill and von Recum, (2008) Effects of electrospinning parameters on fiber morphology are as follow

When applied voltage will increase than fiber diameter will decrease initially than after increase monotonically.

The flow rate will increase than fiber diameter also increases and results in beaded morphologies occur.

The distance among capillary and collector also affect the morphologies of fiber. If distance is high hence the fiber diameter is small and distance is to short beaded morphology will occur.

Polymer concentration will increase than fiber diameter will also increase through the optimal range and solution conductivity increases results in broad diameter distribution found.

The nanofibers are given a combined stretch effect, first, a radial stretch induced by repulsion between the positively charged polymer chains, secondly a longitudinal stretch caused by the excessive collector attraction (Chen 2007).

Advantages of electrospun fiber (Anu, et al., 2014)

\section{Structural advantages}

To produce sub-micron and nanosize fiber, it increase high surface to volume ratio, it gives a tailored morphology and increase porosity and interwined fibrous structure.

\section{Functional advantages}

To prepared products without thermal processes, it minimizes denaturation and sustained and controlled release, it gives 
effective encapsulation and enhanced stability of bioactive and to prepare a food grade polymers and biopolymers.

\section{Applications}

\section{Electrospinning techniques for nanoencapsulation of bioactive compounds}

As per shown in table 1, electrospinning technique used for encapsulation of two different compounds as separated domains inside the single electrospun fiber.

BSA (bovine serum albumin) fluorescently labeled with Texas-Red (BSA-TR) and epidermal growth factor (EGF) fluorescently labeled with Alexafluor 488 (EGFAF488), have been encapsulated in nanoparticles and introduced into electrospun biocompatible PU fibers (Dong et al., 2009).

Electrospinning technique was successfully prepared curcumin or its $\beta$-cyclodextrin $(\beta$ CD) inclusion complexes loaded polyvinyl alcohol (PVA) nanofibers. Curcumin present in the fibers as a crystalline aggregate and $\beta$ $\mathrm{CD}$ complex is greater uniformly distributed and enhanced the thermal stability of curcumin. PVA/curcumin and PVA/complex nanofibers offer improved drug strength and solubility and it shows potential materials used for treating cancers (Sun et al., 2013).

Electrospinning techniques have great potential for encapsulation and stabilization of bioactive antioxidant ( $\beta$-carotene) molecule which is broadly used into the food industry achieved the ultrafine fibers of the zein prolamine have been successful and it is a sustainable agro-polymer to produce micro or nanofiber capsules. The encapsulated $\beta$ carotene gives superior defence against oxidation when exposed to UV-vis irradiation. It means that to enhanced oxidative stability and light stability (Fernandez et al., 2009).
Nanomedicine can be used for engineered nanostructures and nanodevices for checking, repair, development, and management of human biological cycle on the molecular level. By improving the electrospinning parameters to produce hybrid fluorescent curcumin carrying into the zein nanofibrous electrospun scaffold used for biomedical applications and potential for drug delivery system (Brahatheeswaran et al., 2012).

Curcumin having antioxidant, anti-tumor as well as anti-inflammatory properties and it's fabricated into very fine cellulose acetate fiber mat by using electrospinning technique. Curcumin-loaded cellulose acetate fiber having average diameter $340 \mathrm{~nm}$ and curcumin in keeping up its free radical scavenging capability, Stable chemical integrity, and the product was confirmed to be safe to human dermal fibroblasts (Suwantong et al., 2007). To produce a nanoweb having vanillin for enhancing shelf life and stability again high temperature to facilitate by cyclodextrin addition into polyvinyl alcohol (PVA) nanowebs produce by electrospinning technique. This PVA/vanillin/cyclodextrin nanoweb giving an efficient thermal stability and control release of vanillin (Kayaci and Uyar, 2012).

The stabilization and encapsulation of bifidobacterial strains can be also successfully encapsulated into a fiber by Electrospinning technique. The encapsulating material, $\mathrm{PVOH}$ (Polyvinyl alcohol) can be utilized because a great oxygen permeability while dry, and also in water soluble, it can be the easy recovery of bacteria for a viability test with different temperature (room temperature, $4^{\circ} \mathrm{C}$ and $20^{\circ} \mathrm{C}$ ). The cells survived the process in spite of the harsh osmotic change and electrostatic field generated. B. animalis $\mathrm{Bb} 12$ remained viable within the $\mathrm{PVOH}$ fibers at room temperature was 40 days and at refrigeration, conditions were 130 days (Fig. 1 and 2). 
Table.1 Electrospinning techniques for nanoencapsulation of bioactive compound

\begin{tabular}{|c|c|c|c|c|c|}
\hline $\begin{array}{l}\text { Technique } \\
\text { Used }\end{array}$ & $\begin{array}{l}\text { Wall Material } \\
\text { Used }\end{array}$ & $\begin{array}{c}\text { Core } \\
\text { Material }\end{array}$ & $\begin{array}{l}\text { Size } \\
(\mathbf{n m})\end{array}$ & Purpose & Reference \\
\hline \multirow{7}{*}{ 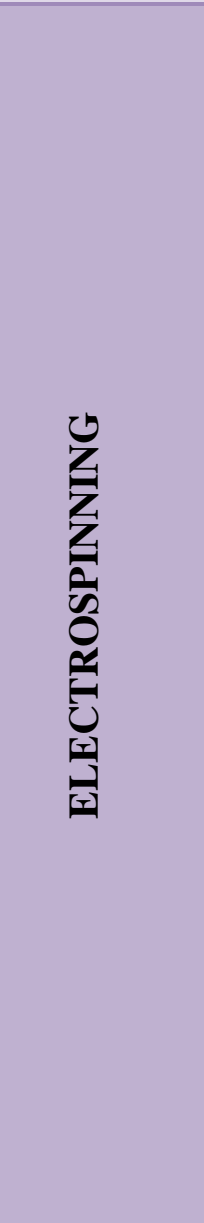 } & Ultrathin & Bifidobacteria & 150 & $\begin{array}{l}\text { Improved viability } \\
\text { of bacteria }\end{array}$ & $\begin{array}{c}\text { Lopez-Rubio et } \\
\text { al., (2009) }\end{array}$ \\
\hline & $\begin{array}{c}\text { Tecophilic } \\
\text { polyurethane }\end{array}$ & $\begin{array}{l}\text { BSA and } \\
\text { epidermal } \\
\text { growth factor }\end{array}$ & 200 & $\begin{array}{l}\text { Encapsulation of } \\
\text { two compounds as } \\
\text { separated domains } \\
\text { within a single } \\
\text { fiber }\end{array}$ & $\begin{array}{l}\text { Dong et al., } \\
\text { (2009) }\end{array}$ \\
\hline & PVA & Curcumin & $\begin{array}{c}250 \\
-350\end{array}$ & $\begin{array}{l}\text { Enhanced stability } \\
\text { of curcumin }\end{array}$ & Sun et al., (2013) \\
\hline & Zeinprolamine & Beta-carotene & $\begin{array}{c}1,14 \\
0\end{array}$ & $\begin{array}{l}\text { Enhanced } \\
\text { oxidative stability } \\
\text { and light stability }\end{array}$ & $\begin{array}{l}\text { Fernandez et al., } \\
\text { (2009) }\end{array}$ \\
\hline & Zein & Curcumin & 310 & $\begin{array}{l}\text { Improved } \\
\text { sustained release } \\
\text { and effective free } \\
\text { radical scavenging } \\
\text { ability }\end{array}$ & $\begin{array}{c}\text { Brahatheeswaran } \\
\text { et al., (2012) }\end{array}$ \\
\hline & $\begin{array}{l}\text { Cellulose } \\
\text { acetate }\end{array}$ & Curcumin & $\begin{array}{c}314 \\
-340\end{array}$ & $\begin{array}{l}\text { Stable chemical } \\
\text { integrity and the } \\
\text { product was } \\
\text { confirmed to be } \\
\text { nontoxic to human } \\
\text { dermal fibroblasts }\end{array}$ & $\begin{array}{l}\text { Suwantong et } \\
\text { al., (2010) }\end{array}$ \\
\hline & $\begin{array}{l}\text { PVA and } \\
\text { cyclodextrin }\end{array}$ & Vanillin & $\begin{array}{c}120 \\
-230\end{array}$ & $\begin{array}{l}\text { Efficient thermal } \\
\text { stability }\end{array}$ & $\begin{array}{c}\text { Kayaci and Uyar } \\
\text { (2012) }\end{array}$ \\
\hline
\end{tabular}

Fig.1 Schematic figure of electrospinning. Reprinted from Sill, T., J., and Vonrecum, H., A., 2008. Electrospinning: Applications in drug delivery and tissue engineering. Biomaterials, 29(13), pp. 1989-2006

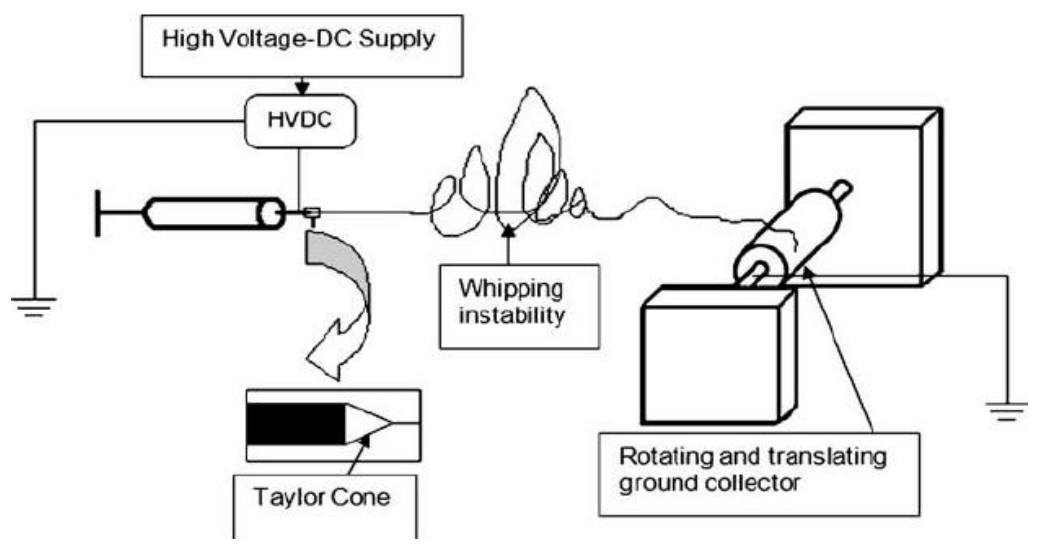


Fig.2 Morphology of electrospun composite biopolymer fiber at egg albumen: PEO ratio of 1:0.3. Reprinted from Wongsasulak, S., Kit, K., M., McClements, D., J., Yoovidhya, T., and Weiss, J., 2007. The effect of solution properties on the morphology of ultrafine electrospun egg albumen-PEO composite fibers. Polymer, 48, 448-457

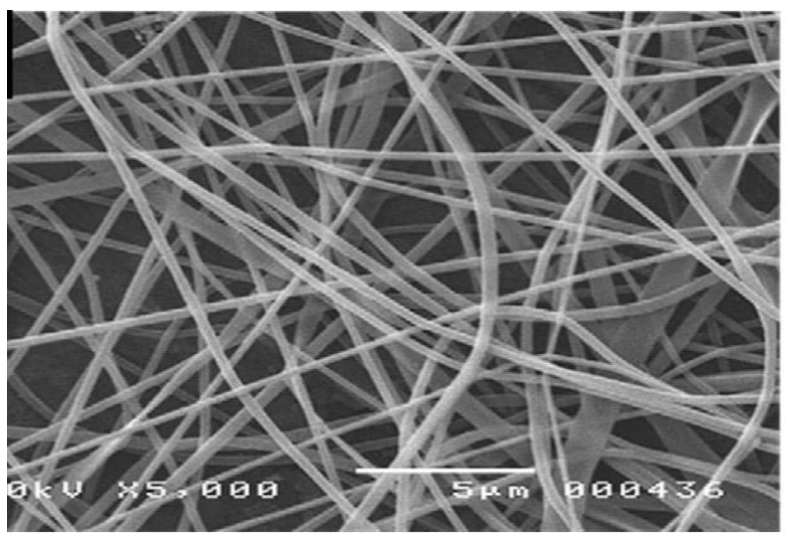

Significant suitability decrease was seen in nonencapsulated bacteria at both temperatures (Lopez-Rubio et al., 2009).

\section{Drug delivery}

Into the electrospun fiber, drugs can be integrated with the help of growing a core/shell shape with a drug solution as the core. This produces a drug release device in which the transport rate is managed by way of the use of the rate of migration of the drug through the wall of the electrospun fiber. The overall release rate can be enhanced by changing the wall thickness of the electrospun fiber (Cornejo et al., 2016).

Coaxial electrospinning can be utilized for encapsulation to decrease injurious because of harsh processing conditions or direct contact along with organic solvents that can occur during conventional emulsification (Jiang et al., 2014). To prepared biodegradable coreshell fibers along with poly (epsiloncaprolactone) as shell and a core of bovine serum albumin (BSA)-containing polysaccharide dextran using coaxial electrospinning technique for controlled release of the payload, proteins were demonstrated (Jiang et al., 2006).
Chymotrypsin is enzymes and it works like a digestive enzyme to evidently produce by using the pancreas can help to breaks down proteins. This enzyme is utilized in the meat and dairy industries as an industrial product, however, are also taken as an enzyme health complement and as a treatment for certain illnesses. The enzyme is specific for peptide bonds with aromatic or massive hydrophobic side chains on the carboxyl side of the bond, as well as catalyzes the hydrolysis of ester bonds. Electrospun enzyme- sporting biocatalyst fibers (Jia et al., 2002).

The protein egg albumen is the source of polymer and it's not capable to form a fiber. So, in this case, a mixing PEO (morphology of electrospun complex biopolymer fiber describe in or cellulose acetate among egg albumen allow the formation of fibers by capturing the protein inside an entangled complex (Wongsasulak et al., 2007).

Other applications of electrospinning technique are used in to produce filters, sensors, biosensors, and protective clothing.

With the help of electrospinning technique produce nanoscale fibers to encapsulate nutrients or food components which can be 
formulated efficiency and at room temperature, which reduce protein denaturation and used for sustained and controlled drug delivery. Moreover, the parameter of electrospinning process i.e., equipment, polymer solution, the environment of this technique can also be variably used to create polymer fiber according to the desired application.

\section{References}

AnuBhushani, J., and Anandharamakrishnan, C. 2014. Electrospinning and electrospraying techniques: Potential food-based applications. Trends in Food Science \& Technology, 38(1), 21-33.

Brahatheeswaran, D., Mathew, A., Aswathy, R.G., Nagaoka, Y., Venugopal, K., Yoshida, Y., Maekawa, T., and Sakthikumar, D. 2012. Hybrid fluorescent curcumin loaded zein electrospun nanofibrous scaffold for biomedical applications. Biomedical Materials, doi: $\quad 10.1088 / 1748-$ 6041/7/4/045001.

Chen, M.J. 2007. Development and Parametric Studies of Carbon Nanotube Dispersion Using Electrospraying. $M S$ Thesis.

Cornejo, B. J. M., Villarreal, G. L. J., and Serrano, M. A. 2016. Electrospinning for Drug Delivery Systems: Drug Incorporation Techniques. Electrospinning - Material, Techniques, and Biomedical Applications. Intech Open.

Dong B., Smith, M.E., and Wnek, G.E. 2009. Encapsulation of Multiple Biological Compounds within a Single Electrospun Fiber. Small, 5(13), 1508-1512.

Doshi, J., and Reneker, D.H. 1995. Electrospinning process and applications of electrospun fibers. Journal of Electrostatics, 35, 151-160.

Fernandez, A., Torresginer, S., and Lagaron,
J.M. 2009. Novel route to stabilization of bioactive antioxidants by encapsulation in electrospun fibers of zein prolamine. Food Hydrocolloids, 23(5), 1427-1432.

Frenot, A., and Chronakis, I.S. 2003. Polymer nanofibers assembled by electrospinning. Current Opinion in Colloid \& Interface Science 8(1), 6475.

Jia, H., Zhu, G., Vugrinovich, B., Kataphinan, W., Reneker, D.H., and Wang, P. 2002. Enzyme carrying polymeric nanofibers prepared via electrospinning for use as unique biocatalysts. Biotechnology Progress, 18, 1027-1032

Jiang, H., Hu, Y., Zhao, P., Li, Y., and Zhu, K. 2006. Modulation of protein release from the biodegradable core-shell structured fibers prepared by coaxial electrospinning. Journal of Biomedical Materials Research Part B: Applied Biomaterials, 79, 50-57.

Jiang, H., Wang, L., and Zhu, K. 2014. Coaxial electrospinning for encapsulation and controlled release of fragile water-soluble bioactive agents. Journal of Controlled Releas, 193, 296303.

Kayaci F., and Uyar, T. 2012. Encapsulation of vanillin/cyclodextrin inclusion complex in electrospun polyvinyl alcohol (PVA) nanowebs: prolonged shelf-life and high-temperature stability of vanillin. Food Chemistry, 133(3), 641-649.

Kessick, R., Fenn, J., and Tepper, G. 2004. The use of AC potentials in electrospraying and electrospinning processes. Polymer, 45(9), 2981-2984.

Lopezrubio, A., Sanchez, E., Sanz, Y., and Lagaron, J.M. 2009. Encapsulation of living bifidobacteria in ultrathin $\mathrm{PVOH}$ electrospun fibers. Biomacromolecules, 10, 2823-2829.

Reneker, D.H., Yarin, A.L., Fong, H., and 
Koombhongse, S. 2000. Bending instability of electrically charged liquid jets of polymer solutions in electrospinning. Journal of Applied Physics, 87, 4531-4547.

Sill, T.J., and Vonrecum, H.A. 2008. Electrospinning: Applications in drug delivery and tissue engineering. Biomaterials, 29(13), 1989-2006.

Sozer, N., and Kokini, J.L. 2009. Nanotechnology and its applications in the food sector. Trends in Biotechnology, 27(2), 82-89.

Sun, X.Z., Williams, G.R., Hou, X.X., and Zhu, L.M. 2013. Electrospun curcuminloaded fibers with potential biomedical applications. Carbohydrate Polymers, 94(1), 147-153.

Suwantong, O., Ruktanonchai, U., and Supaphol, P. 2010. In vitro biological evaluation of electrospun cellulose acetate fiber mats containing asiaticoside or curcumin. Journal of
Biomedical Material Reseach Part A, 94(4), 1216-1225.

Wongsasulak, S., Kit, K.M., McClements, D.J., Yoovidhya, T., and Weiss, J. 2007. The effect of solution properties on the morphology of ultrafine electrospun egg albumen-PEO composite fibers. Polymer, 48, 448-457.

Wu, Y., and Clark, R.L. 2008. Electrohydrodynamic atomization: a versatile process for preparing materials for biomedical applications. Journal of Biomaterials Science, Polymer Edition, 19(5), 573-601.

Yarin, A., Koombhongse, S., and Reneker, D. 2001. Bending instability in electrospinning of nanofibers. Journal of Applied Physics, 89, 3018-3026.

$\mathrm{Yu}$, D.G., Zhu, L.M., White, K., and Branford, W., C. 2009. Electrospun nanofiber-based drug delivery systems. Health, 1(02), 67-75.

\section{How to cite this article:}

Dhaval Raval and Vimal Ramani. 2019. A Review on Electrospinning Technique and Its Application in the Field Of Nanoencapsulation of Bioactive Compounds. Int.J.Curr.Microbiol.App.Sci. 8(07): 2724-2730. doi: https://doi.org/10.20546/ijcmas.2019.807.334 